\title{
In Vivo Insulin Resistance during Pregnancy in the Rat
}

\author{
A. Leturque, P. Ferré, P. Satabin, A. Kervran, and J. Girard \\ Collège de France, Laboratoire de Physiologie du Développement, Paris, France
}

Summary. The glucose disappearance rate measured after IV glucose injection $(1 \mathrm{~g} / \mathrm{kg}$ body $\mathrm{wt})$ remained unchanged between 12 and 21 day of gestation in the rat. In contrast, insulin secretion in response to IV glucose was markedly increased on day 19 and 21 of pregnancy, suggesting resistance to endogenous insulin. Glucose kinetics (glucose production, utilization and clearance) in response to various doses of IV insulin have been studied in anaesthetised postabsorbtive 19 day pregnant and virgin rats using $6-{ }^{3} \mathrm{H}$ glucose. With the supramaximal dose of insulin $(4 \mathrm{U} /$ $\mathrm{kg}$ body wt) no differences in glucose kinetics were found between pregnant and virgin rats. In contrast, with the two lower doses of insulin $(0.15$ and $0.05 \mathrm{U} /$ $\mathrm{kg}$ body wt) glucose production was inhibited by 36 $\pm 3 \%$ and $13 \pm 2 \%$ (Mean \pm SEM) respectively in virgin rats, but was not decreased in pregnant rats. When the effect of insulin on glucose clearance was expressed as \% of the maximal effect obtained with $4 \mathrm{U} / \mathrm{kg}$ body weight, the rise in glucose clearance in response to the two lower doses of insulin $(0.15$ and $0.05 \mathrm{U} / \mathrm{kg}$ body wt) was lower in pregnant $(57.5 \pm 6$ and $27.4 \pm 4 \%)$ than in virgin rats $(73.3 \pm 6$ and $42.2 \pm 7 \%$ ). These results suggest that a decreased sensitivity to insulin appears in late pregnancy in the rat and could involve both liver and skeletal muscle.

Key words: Pregnant rat, insulin resistance, glucose tolerance, glucose production, glucose utilization, glucose turnover, insulin sensitivity.

During human pregnancy there is a progressive and marked increase in plasma insulin secretion in response to IV glucose administration, but glucose tolerance remains within the normal non-pregnant limits $[1,2]$. This suggests that insulin is less effective on the maternal tissues. More recently, using a hyperglycaemic clamp, the maternal tissue sensitivity to endogenous insulin near term was found to be reduced by about $80 \%$ [3]. The progressive nature of the development of resistance to exogenous insulin has been established in a longitudinal study of women during different trimesters of pregnancy [4, 5]. However, as only a single dose of insulin was studied, it is not possible to know if women in late pregnancy would require a larger dose of insulin than non-pregnant women to produce a comparable fall in blood glucose. Moreover, for obvious reasons, it has not been possible to determine the tissue(s) responsible for insulin resistance during human pregnancy.

The only animal species in which studies have been done on insulin resistance in pregnancy is the rat. Costrini and Kalkhoff [6] have demonstrated that overnight fasted 21 day pregnant rats showed normal glucose tolerance after IV glucose injection, despite greater insulin secretion than in virgin rats, thus suggesting decreased sensitivity to endogenous insulin. Knopp et al. [7] have reported that 19 day pregnant rats showed a lower hypoglycaemic response than virgin rats to the IV injection of a large dose of insulin $(10 \mathrm{U} / \mathrm{kg})$, thus suggesting decreased responsiveness to exogenous insulin.

The aims of the present study were to answer the following questions. 1) At what stage of rat pregnancy does insulin resistance appear? 2) Is resistance to exogenous insulin a dose-related phenomenon? 3) What are the tissues responsible for this insulin resistance in vivo?

\section{Methods}

\section{Animals and Diet}

Female Wistar rats bred in our laboratory were used. They were housed at $24^{\circ} \mathrm{C}$ with light from $0700 \mathrm{~h}$ to $1900 \mathrm{~h}$. They had free access to water and chow pellets (65\% carbohydrate, $11 \%$ fat and 
$24 \%$ protein). The average number of fetuses per pregnant rat was 10 and rats with less than 8 fetuses were not included. Virgin female rats age-matched with pregnant rats were used as nonpregnant controls. The stage of pregnancy was determined as described previously [8].

\section{Intravenous Glucose Tolerance Test}

All the tests were performed at $0900 \mathrm{~h}$, that is in the fed state since spontaneous food consumption in virgin or pregnant rats stopped at $0700 \mathrm{~h}$ with the onset of lighting. The rats were anaesthetized with pentobarbitone $(30 \mathrm{mg} / \mathrm{kg}$ body weight IP) and one carotid artery was catheterised. Body temperature was continuously recorded with a telethermometer (Yellow Spring Instrument, Yellow Spring, Ohio) and maintained at $37^{\circ}-38^{\circ} \mathrm{C}$ using heating lamps. A $50 \mathrm{~g} / 100 \mathrm{ml}$ glucose solution was injected rapidly into the saphenous vein in a dose of $1 \mathrm{mg} / \mathrm{g}$ body weight. Arterial blood samples $(100 \mu \mathrm{l})$ were collected before, and 5, 10, 15, 20, 25 and $30 \mathrm{~min}$ after glucose injection. An aliquot of blood was immediately deproteinized in barium hydroxide $(0.083 \mathrm{~mol} / \mathrm{l})$ zinc sulphate $(0.087 \mathrm{~mol} / \mathrm{l})$ for subsequent determination of glucose by a glucose oxidase method [8]. The remaining blood was centrifuged immediately at $4{ }^{\circ} \mathrm{C}$ and the plasma frozen at $-20^{\circ} \mathrm{C}$ for subsequent determination of insulin by a radioimmunoassay using rat insulin as standard [8].

The insulin response during the glucose tolerance tests was calculated as an insulinogenic index $(\Delta \mathrm{I} / \Delta \mathrm{G})$ : the ratio of the increase in plasma insulin concentration $(\Delta \mathrm{I})$, above the preinjection value, integrated over the $30 \mathrm{~min}$ after injection of glucose, to the corresponding increase in glucose concentration $(\Delta G)$ over the same period. The rate of glucose disappearance $(\mathrm{K})$ was calculated according to the formula: $\frac{\mathrm{K}=2.303\left(\log \mathrm{G}_{1}-\log \mathrm{G}_{2}\right)}{\mathrm{t}_{2}-\mathrm{t}_{1}}$

and was expressed in $\% \min ^{-1} \cdot G_{1}$ and $G_{2}$ represent blood glucose concentrations at times $t_{1}$ and $t_{2}$.

\section{Effects of Exogenous Insulin on the Rate of Glucose Production and Utilization and on the Metabolic Clearance Rate of Glucose}

These studies were performed at $1400 \mathrm{~h}$ in rats fasted from $0700 \mathrm{~h}$. After $7 \mathrm{~h}$ of fasting, the difference in glucose concentration between the carotid artery and the portal vein was always positive $(+0.27 \pm 0.08 \mathrm{mmol} / \mathrm{l})$ both in pregnant and virgin rats, indicating that the gut was using glucose and not adding glucose into the portal circulation from previously ingested food. In these conditions, the rate of glucose production was a measure of endogenous glucose production.

Rats were anaesthetised with pentobarbitone and one carotid artery was catheterised for blood sampling. Radioactive glucose and insulin (Porcine monocomponent insulin, Novo Industri, Copenhagen) were infused or injected through the saphenous vein. The same dose of insulin per $\mathrm{kg}$ body weight was injected in both pregnant and virgin rats as it has been shown that after $200 \mathrm{mU} / \mathrm{kg}$ IV insulin in $20 \mathrm{~d}$ pregnant or virgin rats, plasma insulin concentrations were similar in both groups until 15 min after the injection [9]. In our experiments, the most marked changes in glycaemia and glucose kinetics occured in the $15 \mathrm{~min}$ after insulin injection both in pregnant and virgin rats. These changes in insulin degradation rate are not likely to affect the results obtained. A priming dose of $\left[6{ }^{3} \mathrm{H}\right]$-glucose (Amersham, Radiochemical Centre, UK) was administered rapidly and followed by continuous tracer infusion at a rate of $4 \mu \mathrm{Ci} / \mathrm{min}$. The priming dose was 20 fold greater than the continuous infusion rate/min. In these conditions, plasma specific activity of the $\left[6-{ }^{3} \mathrm{H}\right]$-glucose reached a stable plateau at $40 \mathrm{~min}$. The coefficient of variation of glucose specific activity during the final $10 \mathrm{~min}$ of the equilibration period was $6.6 \pm 0.8 \%$ (mean $\pm \mathrm{SEM}$ ). Insulin was injected 50 min after the beginning of the $\left[6{ }^{3} \mathrm{H}\right]$-glucose infusion and blood was sampled every 2 min thereafter unless otherwise indicated.

Blood samples $(50 \mu \mathrm{l})$ were deproteinized. After centrifugation $(16000 \mathrm{~g}$ for $2 \mathrm{~min}$ ) an aliquot of supernatant was used for glucose determination and a further aliquot was evaporated to dryness at $70{ }^{\circ} \mathrm{C}$ to remove ${ }^{3} \mathrm{H}_{2} \mathrm{O}$. The dry residue was dissolved in $0.2 \mathrm{ml}$ water and counted with $10 \mathrm{ml}$ of PCS (Radiochemical Centre Amersham, England) in a liquid scintillation spectrometer (Nuclear Chicago Corp., Des Plaines, Ill.). In preliminary experiments using $\left[6{ }^{3} \mathrm{H}\right]-$ glucose, aliquots of blood barium hydroxide zinc sulphate filtrates were treated as follows: an aliquot was directly evaporated to dryness and another aliquot was passed through a column of ion-exchange resin (Dowex AG1 $\times 8$, formate-form, and Dowex AG $50 \times 8, \mathrm{H}^{+}$form) in order to remove possible ${ }^{3} \mathrm{H}$ containing material (lactate, pyruvate) other than glucose and water. The effluent from the column was then evaporated to dryness. Specific activity of ${ }^{3} \mathrm{H}$ glucose passed through the column was found to be $98 \pm 2 \%(\mathrm{n}=10)$ of the specific activity of ${ }^{3} \mathrm{H}$ glucose not passed through the column. The passage through ionexchange resins was then discontinued.

Rates of endogenous glucose production and utilization were calculated in the steady state before insulin injection by the isotope dilution equation, and during non-steady state conditions by Steele's equations in their derivative form [10]. The time curves for glucose concentration and specific activity were fitted with polynomial functions by the method of least squares. The value of 0.75 (pool fraction) was used to correct for non instantaneous mixing within the entire glucose pool [11]. Glucose space was $25 \pm 2 \%$ of body weight $(n=7)$ in pregnant rats and $26 \pm 1 \%$ $(n=8)$ in virgin rats.

The evaluation of the rates of glucose turnover based on primed continuous infusion and the pool fraction technique have been validated for both steady and non-steady states [12]. Glucose clearance was calculated as the ratio of the rate of glucose utilization and blood glucose concentration, and normalized to body weight. Glucose clearance has been used as an index of the ability of tissues to remove glucose from plasma independently of plasma glucose concentration [13]. All calculations were performed on a Hewlett-Packard 97 calculator (Hewlett-Packard Co, Palo Alto, Calif.).

\section{Statistics}

Results are expressed as mean \pm SEM. Because the small sample size used precluded determining the normality of the population distribution, significance was assessed using the Wilcoxon rank order test [14].

\section{Results}

\section{Intravenous Glucose Tolerance Test (IVGTT)}

IVGTTs were performed in pregnant rats at 12,16 , $17,18,19,20$ and 21 days of gestation. Virgin rats age-matched with pregnant rats were used as controls. There was no significant difference in the disappearance rates of glucose ( $\mathrm{K}$ value) between pregnant and virgin rats (Table 1 ). The insulin secretion in response to IV glucose was not different in virgin and pregnant rats on days 12 and 16 of gestation 
Table 1. Glucose disappearance rate (K) and insulinogenic index $\Delta \mathrm{I} / \Delta \mathrm{G}$ (calculated from areas of insulin and glucose) in response to IV glucose $(1 \mathrm{~g} / \mathrm{kg}$ body wt) at different stages of pregnancy and in virgin rats

\begin{tabular}{|c|c|c|c|c|c|c|c|c|}
\hline \multirow{4}{*}{$\begin{array}{l}\triangle \mathrm{I} / \triangle \mathrm{G} \\
\mathrm{K}\left(\% \mathrm{~min}^{-1}\right)\end{array}$} & \multirow{3}{*}{$\begin{array}{l}\text { Virgin } \\
1.1 \pm 0.2\end{array}$} & \multicolumn{7}{|l|}{ Pregnant } \\
\hline & & 12 days & 16 days & 17 days & 18 days & 19 days & 20 days & 21 days \\
\hline & & $1.2 \pm 0.2$ & $1.2 \pm 0.3$ & $1.9 \pm 0.3^{\mathrm{a}}$ & $2.0 \pm 0.1^{\mathrm{a}}$ & $2.3 \pm 0.3^{b}$ & $1.9 \pm 0.2^{\mathrm{a}}$ & $1.8 \pm 0.2^{\mathrm{a}}$ \\
\hline & $4.8 \pm 0.2$ & $5.3 \pm 0.3$ & $4.4 \pm 0.3$ & $4.7 \pm 0.5$ & $5.0 \pm 0.1$ & $5.2 \pm 0.2$ & $4.6 \pm 0.6$ & $5.3 \pm 0.3$ \\
\hline
\end{tabular}

Values are means \pm SEM of 8 to 14 observations

a $<0.05$ and $^{\mathrm{b}} \mathrm{P}<0.01$ when compared with virgin rats
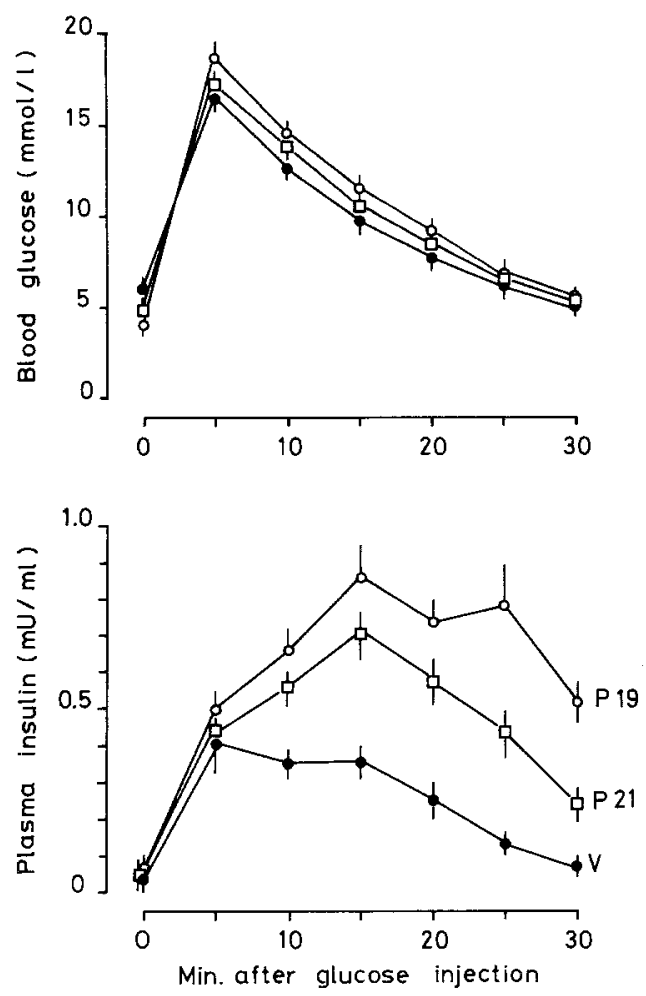

Fig. 1. Intravenous glucose tolerance test $(1 \mathrm{~g} / \mathrm{kg}$ body $\mathrm{wt})$. (- Virgin rats, $(\mathrm{O}-\mathrm{O}) 19$ day pregnant rats (P 19), $(\square-\square$ ) 21 day pregnant rats (P 21). Values are mean \pm SEM of 8 to 14 determinations

(Table 1). By contrast, insulin secretion was markedly enhanced in pregnant rats on days $17,18,19$, 20 and 21 of gestation (Table 1, Fig. 1).

\section{Effects of Exogenous Insulin on the Rates} of Endogenous Glucose Production and Utilization and on the Metabolic Clearance Rate (MRC) of Glucose in Virgin and 19 Day Pregnant Rats

The effects of various doses of exogenous insulin on the rates of endogenous glucose production and utilization were studied in 19 day pregnant and age-

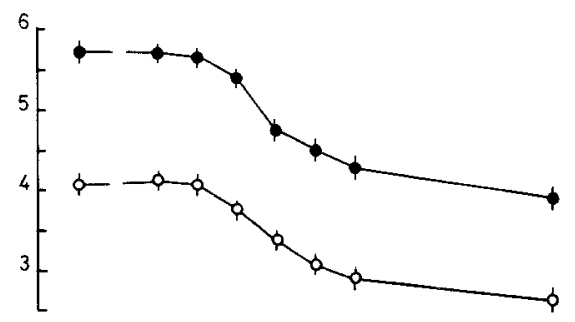

GLUCOSE PRODUCTION $\mu \mathrm{mol} / \mathrm{kg} / \mathrm{min}$
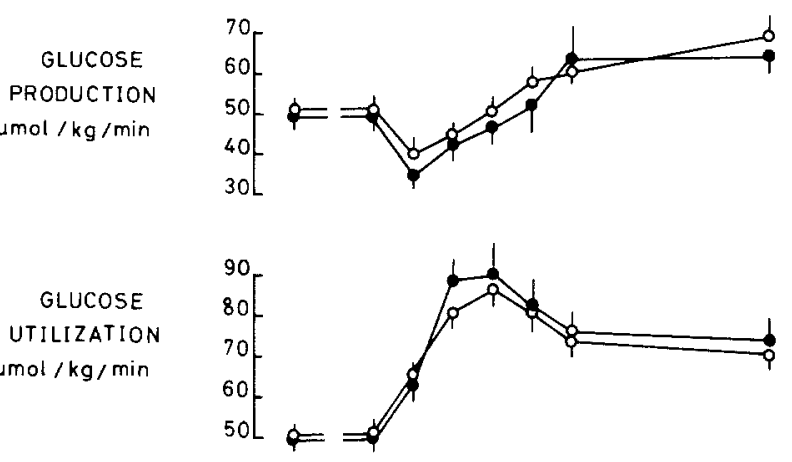

GLUCOSE CLEARANCE $\mathrm{ml} / \mathrm{kg} / \mathrm{min}$

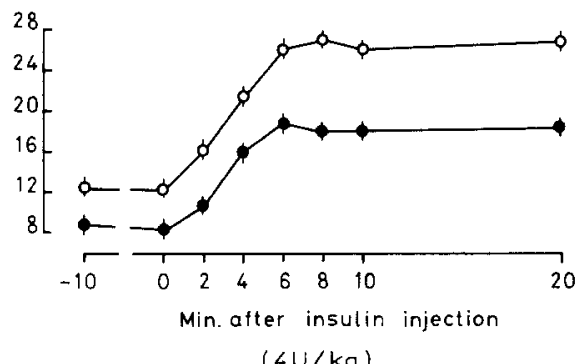

$(4 \cup / \mathrm{kg})$

Fig. 2. Effects of IV insulin injection ( $4 \mathrm{U} / \mathrm{kg}$ body wt) on blood glucose and glucose kinetics in virgin (-_- ) and 19 day pregnant rats $(\mathrm{O}-\mathrm{O})$. Values are mean \pm SEM of 8 determinations

matched virgin rats. In preliminary experiments, the" maximal lowering effect of exogenous insulin on glycaemia was obtained in both virgin and 19 day pregnant rats at a dose of $1 \mathrm{U} / \mathrm{kg}$ body wt injected IV.

In order to determine whether insulin resistance occured irrespective of the insulin dose, or whether it was restricted to only low doses, the effects of 3 doses 


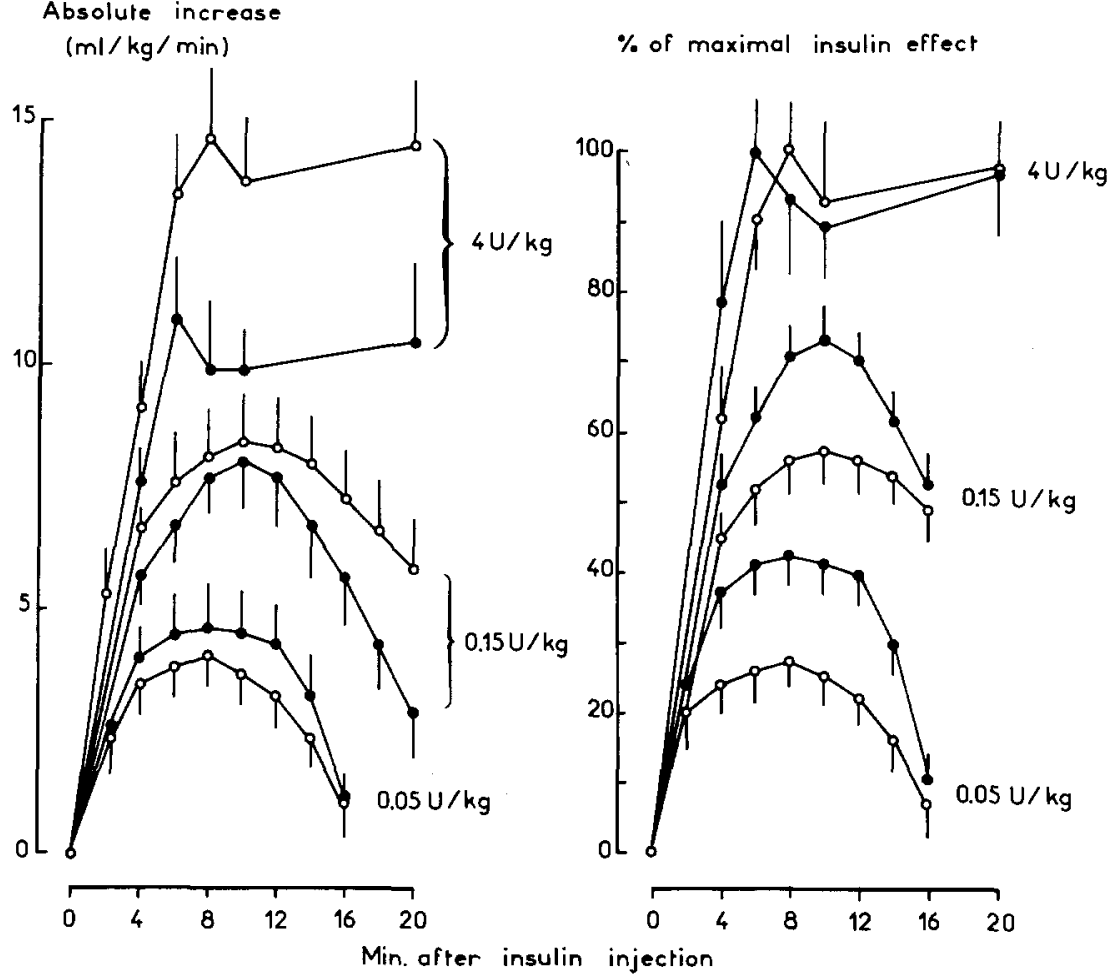

Fig. 3. Effects of various doses of insulin ( $4 \mathrm{U} / \mathrm{kg}, 0.15 \mathrm{U} / \mathrm{kg}$ and $0.05 \mathrm{U} / \mathrm{kg}$ body wt) on absolute increase and on the \% of maximal insulin effect on glucose clearance. $(-0)$ virgin rats, $(\mathrm{O}-\mathrm{O}) 19$ day preg. nant rats. Values are mean \pm SEM of 6 to 8 determinations of insulin were studied: a supramaximal dose $(4 \mathrm{U} / \mathrm{kg}$ body wt) and 2 submaximal doses $(50$ and $150 \mathrm{mU} /$ $\mathrm{kg}$ body wt).

Effects of Insulin at a Dose of $4 \mathrm{U} / \mathrm{kg}$ Body Wt. The injection of insulin at a dose of $4 \mathrm{U} / \mathrm{kg}$ body wt resulted in a similar decrease in blood glucose concentration in virgin $(1.7 \pm 0.1 \mathrm{mmol} / \mathrm{l})$ and 19 day pregnant $(1.5 \pm 0.2 \mathrm{mmol} / \mathrm{l})$ rats at $20 \mathrm{~min}$ (Fig. 2 ). At $2 \mathrm{~min}$, endogenous glucose production fell by 25 $\pm 9 \%$ in virgin rats (basal value $47 \pm 2 \mu \mathrm{mol} / \mathrm{kg}$ / $\mathrm{min}$ ) and by $20 \pm 7 \%$ in pregnant rats (basal value 51 $\pm 2 \mu \mathrm{mol} / \mathrm{kg} / \mathrm{min}$ (Fig. 2). Beyond $2 \mathrm{~min}$, endogenous glucose production rose rapidly both in virgin and pregnant rats and reached at 10 to 20 min values which were respectively $39 \pm 5 \%$ and $37 \pm 6 \%$ higher than basal values. Glucose utilization rose markedly within 6 minutes both in virgin $(95 \pm 17 \%)$ and pregnant $(70 \pm 6 \%)$ rats and then progressively decreased between 6 and $20 \mathrm{~min}$ (Fig. 2). Glucose clearance was higher in the basal state in pregnant rats when compared to virgin rats, $12.4 \pm 0.6 \mathrm{ml} /$ $\mathrm{min} / \mathrm{kg}$ versus $8.1 \pm 0.3(\mathrm{P}<0.01)$ (Fig. 2$)$. The maximal absolute increase in glucose clearance after insulin injection was higher $(15 \pm 1.5 \mathrm{ml} / \mathrm{min} / \mathrm{kg})$ in pregnant rats at $8 \mathrm{~min}$ than in virgin rats $(10.9 \pm$ $1.6 \mathrm{ml} / \mathrm{min} / \mathrm{kg}$ ) at $6 \mathrm{~min}(\mathrm{P}<0.05)$ (Fig. 3$)$.

Glucose clearance then remained at these values until $20 \mathrm{~min}$ for both groups.
Effects of Insulin at a Dose of $150 \mathrm{mU} / \mathrm{kg}$ Body Wt. The injection of insulin at a dose of $150 \mathrm{mU} / \mathrm{kg}$ produced a lesser decrease $(P<0.05)$ in blood glucose concentration in pregnant $(0.5 \pm 0.07 \mathrm{mmol} / \mathrm{l})$ than in virgin $(0.99 \pm 0.17 \mathrm{mmol} / 1)$ rats at $10 \mathrm{~min}$ (Fig. 4). At 2 min endogenous glucose production fell by $36 \pm$ $7 \%$ in virgin rats (basal value $58 \pm 4 \mu \mathrm{mol} / \mathrm{kg} / \mathrm{min}$ ).; by contrast, there was no significant decrease in pregnant rats (Fig. 4). Beyond 2 min endogenous glucose production rose rapidly both in virgin and pregnant rats to reach at 14 and 20 min values respectively 34 $\pm 7 \%$ and $34 \pm 4 \%$ higher than basal rates (Fig. 4 ). The maximal rise of glucose utilization was statistically different $(P<0.02)$ in pregnant, $33 \pm 4 \%$ at $8 \mathrm{~min}$, compared to virgin rats, $50 \pm 5 \%$ at $6-8 \mathrm{~min}$. Glucose clearance rose by $8.4 \pm 1.0 \mathrm{ml} / \mathrm{min} / \mathrm{kg}$ in pregnant rats at $10 \mathrm{~min}$ and by $8.0 \pm 1.0 \mathrm{ml} / \mathrm{min} / \mathrm{kg}$ in virgin rats at $10 \mathrm{~min}$ (Fig. 3). When the effect of insulin on glucose clearance was expressed as \% of the maximal effect obtained at $4 \mathrm{U} / \mathrm{kg}$ body weight, the maximal rise was $57.5 \pm 6 \%$ at $10 \mathrm{~min}$ in pregnant rats and $73.3 \pm 6 \%$ at $10 \mathrm{~min}$ in virgin rats (Fig. 3). This difference was statistically significant $(\mathrm{P}<0.05)$.

Effects of Insulin at a Dose of $50 \mathrm{mU} / \mathrm{kg}$ Body Wt. The injection of insulin at a dose of $50 \mathrm{mU} / \mathrm{kg}$ produced in $8-10 \mathrm{~min}$ a lower decrease $(\mathrm{P}<0.01)$ in blood glucose concentration in pregnant $(0.24 \pm$ 


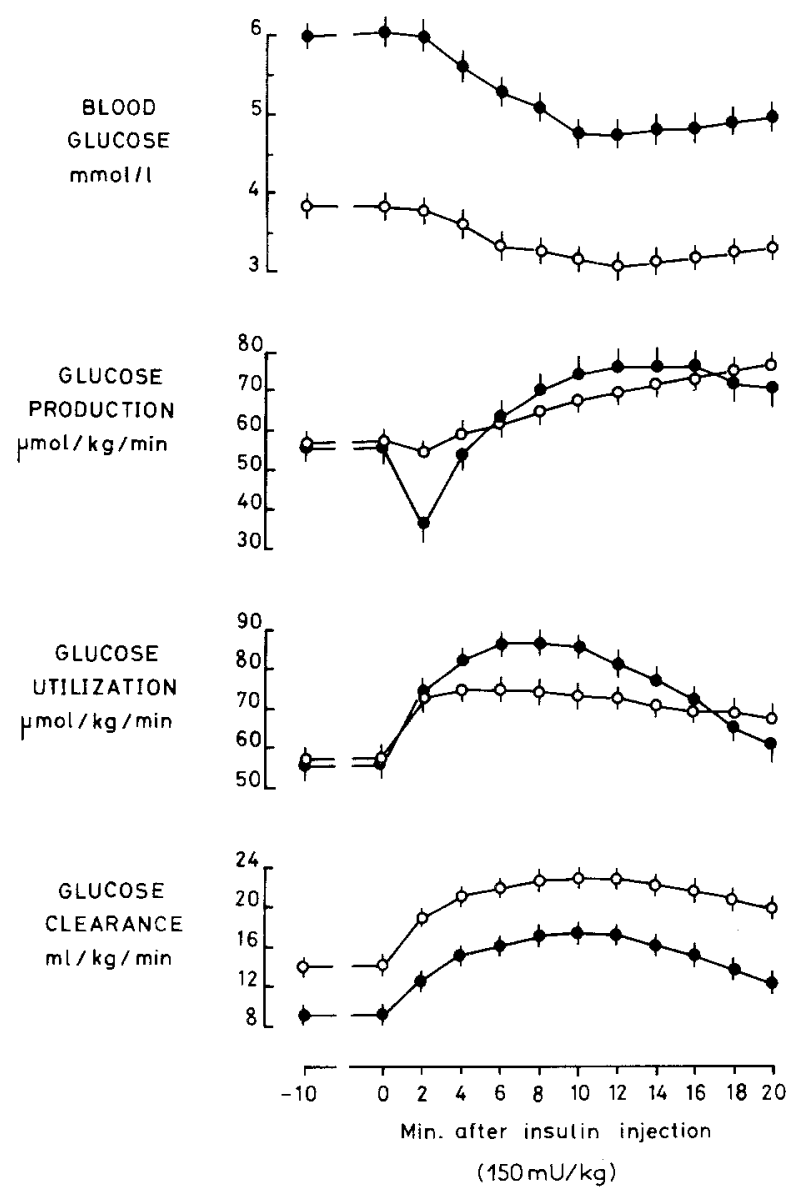

Fig. 4. Effects of IV insulin injection $(0.15 \mathrm{U} / \mathrm{kg}$ body wt) on blood glucose and glucose kinetics in virgin (- $)$ and 19 day pregnant rats $(\mathrm{O}-\mathrm{O})$. Values are mean \pm SEM of 6 determinations

$0.03 \mathrm{mmol} / \mathrm{l})$ than in virgin rats $(0.71 \pm 0.07 \mathrm{mmol} / \mathrm{l})$ (Fig. 5). At $2 \mathrm{~min}$, endogenous glucose production fell by $13 \pm 4 \%$ in virgin rats (basal value $55 \pm$ $1 \mu \mathrm{mol} / \mathrm{kg} / \mathrm{min}$ ). By contrast, there was no significant decrease in pregnant rats (Fig. 5). Endogenous glucose production then rose rapidly both in virgin and pregnant rats to reach at 14 minutes values $40 \pm 5 \%$ and $39 \pm 8 \%$ higher than basal rates respectively. The maximum increase of glucose utilization was reached at $8 \mathrm{~min}$ in both groups and was similar, 30 $\pm 7 \%$ in virgin versus $24 \pm 4 \%$ in pregnant rats (Fig. 5). Thereafter it returned to basal values at $16 \mathrm{~min}$. Glucose clearance rose by $4.0 \pm 0.5 \mathrm{ml} / \mathrm{min} /$ $\mathrm{kg}$ in pregnant rats at $8 \mathrm{~min}$ and by $4.6 \pm 0.9 \mathrm{ml} / \mathrm{min} /$ $\mathrm{kg}$ in virgin rats at $8 \mathrm{~min}$ (Fig. 3). The maximal rise in glucose clearance when expressed as percent of maximal insulin effect was $27.4 \pm 4 \%$ at $8 \mathrm{~min}$ in pregnant rats and $42.2 \pm 7 \%$ at $8 \mathrm{~min}$ in virgin rats (Fig. 3). This difference was statistically significant $(\mathrm{P}<0.05)$.

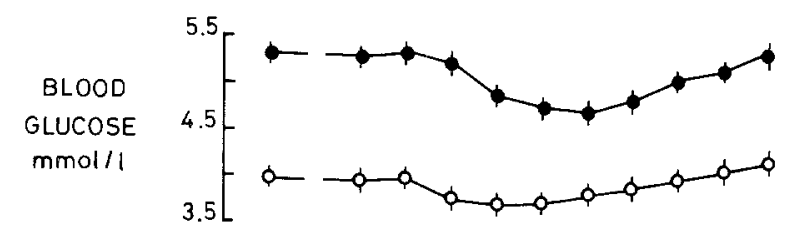

\section{GLUCOSE} PRODUCTION $\mu \mathrm{mol} / \mathrm{kg} / \mathrm{min}$

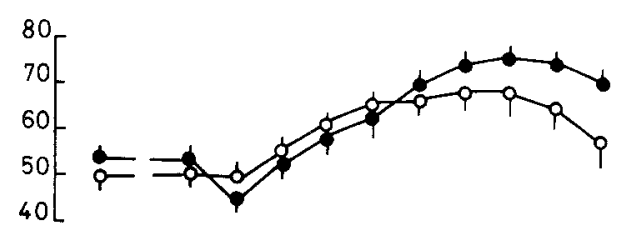

GLUCOSE
UTILIZATION
Hmol/kg/min

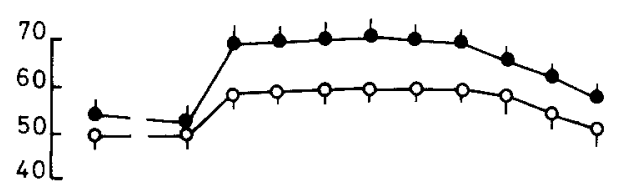

$$
\begin{aligned}
& \text { GLUCOSE } \\
& \text { CLEARANCE } \\
& \mathrm{ml} / \mathrm{kg} / \mathrm{min}
\end{aligned}
$$

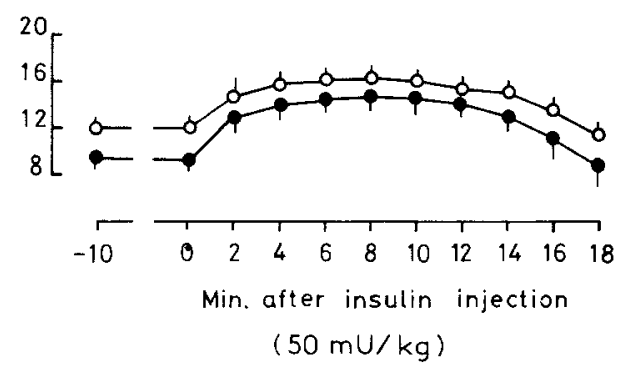

Fig. 5. Effects of IV insulin injection $(0.05 \mathrm{U} / \mathrm{kg}$ body wt) on blood glucose and glucose kinetics in virgin (-@) and 19 day pregnant rats $(\mathrm{O}-\mathrm{O})$. Values are mean \pm SEM of 6 determinations

\section{Discussion}

\section{Intravenous Glucose Tolerance}

Our studies show that the rates of glucose disappearance after IV glucose injection ( $K$ value) do not change in the last half of pregnancy in the rat and are identical to non-pregnant controls. The $\mathrm{K}$ value found in anaesthetized virgin rats $4.8 \pm 0.2 \% \mathrm{~min}^{-1}$ was higher than the $K$ value found in unanaesthetized unstressed rats : $3.0 \pm 0.3 \% \mathrm{~min}^{-1}[15]$ and much higher than the $\mathrm{K}$ value measured in unanaesthetized stressed rats $2.2 \pm 0.2 \% \mathrm{~min}^{-1}$ [15]. This suggests that anaesthesia did not grossly modify glucose tolerance in our experiments. Our data show that enhanced insulin secretion is required after day 16 of pregnancy to allow normal glucose utilization after IV glucose injection. This confirms previous studies [6] and demonstrates that resistance to endogenous insulin develops between day 16 and 19 of pregnancy 
in the rat and then decreases slightly at term (21 days).

Modifications of glucose metabolism during pregnancy in the rat bear comparison with changes observed in women. A progressive increase in insulinogenic response to IV glucose has been observed in pregnant women as term approaches, while the $K$ value is not very different from the value measured in non-pregnant women [1.2].

\section{Effects of Exogenous Insulin on Blood Glucose Levels}

Earlier work has shown that large doses of insulin $(10 \mathrm{U} / \mathrm{kg}$ body wt) produced a smaller decrease of blood glucose in pregnant than in virgin rats [7]. This is not in agreement with the present studies. When insulin was injected at a relatively large dose $(4 \mathrm{U} / \mathrm{kg}$ body wt), the hypoglycaemic effect was the same in pregnant and in virgin rats (Fig. 2). However, when low doses of exogenous insulin were used (50 or $150 \mathrm{mU} / \mathrm{kg}$ body wt) a smaller hypoglycaemic effect was observed in pregnant than in virgin rats. The discrepancy between our results and those previously published [7] using large dose of insulin could result from differences in experimental protocols. We used anaesthetized rats, but it has been shown that glucose tolerance is not grossly modified in these conditions (see preceding paragraphs). In contrast, other authors used unanaesthetized rats which were probably stressed by the sampling procedure used (collection of blood after cutting the tail tip), and a mild stress in unanaesthetized rats has been shown to produce a decrease in glucose tolerance [15]. Moreover, the particular sensitivity of the adrenal glands of pregnant rats to stressful situations $[16,17]$ could have decreased glucose tolerance more efficiently in pregnant than in virgin rats.

In any case, these studies lead to different conclusions. The study of Knopp et al. [7] showed that a large dose of insulin was unable to produce a quantitatively normal fall of blood glucose in pregnant rats. This suggests that there is a decreased responsiveness to insulin during pregnancy according to the classification proposed by Kahn [18]. In contrast our studies show that relatively low doses of insulin produce a smaller fall in glycaemia during pregnancy but that a large dose of insulin produces a normal hypoglycaemic response in pregnant rats. This suggests decreased sensitivity to insulin as the mechanism responsible for insulin resistance during pregnancy. The fact that a normal glucose disappearance is achieved in late gestation by a compensatory increase in insulin secretion fits well with this conclusion.
In our studies, the smaller blood glucose lowering capacity of the 2 low doses of exogenously injected insulin in pregnant rats could result from several factors: 1) the presence of the fetuses which represent a mass of tissue not affected by insulin injected to the mother, but which could decrease their glucose utilization during maternal hypoglycaemia; 2) a more rapid and efficient secretion of counterregulatory hormones preventing hypoglycaemia because of a more marked stimulation of glucose production; 3 ) a decreased sensitivity of liver or peripheral tissues (muscle, adipose tissue) to the exogenously administered insulin. To answer these questions, it was necessary to study the changes in glucose kinetics in response to administered insulin.

\section{Effects of Exogenous Insulin on Glucose Kinetics}

The glucose kinetics observed after insulin injection in virgin rats are in agreement with the data obtained previously by Sacca et al. [11] in the adult male rat injected with a dose of insulin of $150 \mathrm{mU} / \mathrm{kg}$ body wt.

After injection of the highest dose of insulin ( $4 \mathrm{U} / \mathrm{kg}$ body wt), the rate of glucose production and utilization were modified in a similar fashion in pregnant and in virgin rats. This suggests that insulin resistance of pregnancy is not related to decreased responsiveness since it can be overcome by using a large dose of insulin. If resistance to exogenously administered insulin was only the result of a decreased fetal glucose utilization secondary to hypoglycaemia, it would be expected that this effect would be predominant with the greatest hypoglycaemia that is after injection of the highest dose of insulin. Since this was not the case, possible decrease in fetal glucose utilization can be rejected as a factor contributing to insulin resistance.

The pregnant rats are characterized by the absence of a rapid decrease in endogenous glucose production after injection of low doses of insulin (Figs. 4 and 5). This could be due to a very rapid hormonal counterregulation or to a decreased sensitivity of the liver to insulin as this organ is responsible for $80 \%$ of endogenous glucose production during the postabsorptive period [19]. As a rapid decrease in endogenous glucose production occurs in pregnant rats after the high dose of insulin and as maximal counterregulation could be expected in such a situation, decreased liver sensitivity to insulin seems more likely. This decreased sensitivity of liver to insulin during late pregnancy could involve a decrease in hepatic insulin receptors [20], although other investigators have found no change [21] or an increase [22] in insulin binding to liver membranes in pregnant rats. 
Glucose clearance is a more useful index of the ability of tissues to remove glucose from plasma since it is independent of changes in blood glucose concentration [13]. Glucose clearance in the basal state was $40 \%$ higher per unit of body weight in pregnant than in virgin rats. Calculations from data published in the literature $[23,24]$ show that the same is true in sheep (glucose clearance in twin-pregnant sheep is 3.9 versus $2.4 \mathrm{ml} / \mathrm{min} / \mathrm{kg}$ in non pregnant, a $62 \%$ increase) and in women $(4.2 \mathrm{ml} / \mathrm{min} / \mathrm{kg}$ in pregnant women, vs 3.1 in nonpregnant, a $35 \%$ increase). This indicates the presence of a site of high glucose utilization in the pregnant organism, which could be the conceptus. Indeed glucose utilization in fetal sheep at term is $4.8 \mathrm{mg} / \mathrm{min} / \mathrm{kg}$ [25] a figure much higher than glucose utilization in adult sheep: $1.5 \mathrm{mg} / \mathrm{min} / \mathrm{kg}$ [23].

The absolute increase in glucose clearance in response to the supramaximal dose of insulin $(4 \mathrm{U} / \mathrm{kg}$ body weight) was higher in pregnant than in virgin rats. This could result from the larger mass of insulindependent tissues (muscles, adipose tissue, mammary gland, placenta) which are present in late pregnancy $[26,27]$. However, when it was expressed in $\%$ of the maximal effect, the increase in glucose clearance in response to the 2 lower doses of insulin was lower in pregnant than in virgin rats. This suggests that there is a decrease in glucose utilization in peripheral tissues of the pregnant rats. As skeletal muscles represent $40 \%$ of body weight in the rat and contribute to the disposal of $35 \%$ of an IV administered glucose load in the rat [28], they probably contribute to the observed insulin resistance. Recently, it has been reported that insulin binding to soleus muscle was decreased by $50 \%$ in pregnant rats and this was accompanied by a $50 \%$ lower insulin-stimulated 2deoxyglucose uptake [21]. Moreover, the stimulation of glucose uptake by insulin in perfused hindlimb is $40-50 \%$ lower in pregnant than in non-pregnant rats [29]. These data clearly show that skeletal muscle participates in insulin resistance during pregnancy in the rat. Adipose tissue is another insulin-dependant tissue which contributes to $5-10 \%$ of the disposal of an IV administered glucose load in the rat [28]. In vitro studies indicate that insulin promotes greater uptake [30] and metabolism [31] of glucose in adipose tissue of pregnant than in virgin rats. More recently, an increased number of insulin receptors have been found in adipose tissue of pregnant rats [32]. These data exclude adipose tissue as the site of insulin resistance in pregnancy.

In summary, these studies provide an answer to the three major questions addressed in the introduction. First, insulin resistance develops between day 16 and 19 of pregnancy in the rat. Second, one may consider insulin resistance in pregnancy as a state of decreased sensitivity to insulin; indeed at the level of the whole organism, a quantitatively normal response to insulin can be achieved when greater than normal amounts of insulin are present. Third, insulin resistance in pregnancy involves both glucose-producing and glucose-utilizing tissues.

Acknowledgements. This investigation has been supported in part by the Délégation Générale à la Recherche Scientifique et Technique (Grant 76-7-1539).

\section{References}

1. Pedersen J (1977) The pregnant diabetic and her newborn. Munksgaard, Copenhagen, p 22-30

2. Kalkhoff RK, Kissebah AH, Kim HJ (1978) Carbohydrate and lipid metabolism during normal pregnancy: relationship to gestational hormone action. Semin Perinatol 2: 291-308

3. Fisher PM, Sutherland HW, Bewsher PD (1979) Insulin response studies in normal pregnancy and chemical gestational diabetes. In: Sutherland HW, Stowers JM (ed) Carbohydrate metabolism in pregnancy and the newborn, 1978. Springer, Berlin Heidelberg New York p 47-61

4. Burt RL (1956) Peripheral utilization of glucose in pregnancy III) Insulin tolerance. Obstet Gynecol 2: 658-664

5. Yen SSC (1973) Endocrine regulation of metabolic homeostasis during pregnancy. Clin Obstet Gynecol 16: 130-147

6. Costrini NV, Kalkhoff RK (1971) Relative effects of pregnancy, estradiol and progesterone on plasma insulin and pancreatic islet insulin secretion. J Clin Invest 50: 992-999

7. Knopp RH, Ruder HJ, Herrera E, Freinkel N (1970) Carbohydrate metabolism in pregnancy VII) Insulin tolerance during late pregnancy in the fed and fasted rat. Acta Endocrinol (Kbh) 65: 352-360

8. Girard JR, Cuendet GS, Marliss EB, Kervran A, Rieutort M, Assan R (1973) Fuels, hormones and liver metabolism at term and during the early postnatal period in the rat. $\mathrm{J}$ Clin Invest 52: $3190-3200$

9. Katz AI, Lindheimer MD, Mako ME, Rubenstein AH (1975) Peripheral metabolism of insulin, proinsulin and C-peptide in the pregnant rat. J Clin Invest 56: 1608-1614

10. Steele R (1959) Influences of glucose loading and of injected insulin on hepatic glucose output. Ann NY Acad Sci 82: $420-430$

11. Sacca L, Perez G, Carteni G, Rengo F (1977) Evaluation of the role of the sympathetic nervous system in the glucoregulatory response to insulin-induced hypoglycemia in the rat. Endocrinology 101: 1016-1022

12. Radziuck J, Norwich KH, Vranic M (1978) Experimental validation of measurements of glucose turnover in nonsteady state. Am J Physiol 234: E84-E93

13. Cherrington AD, Williams PE, Harris MS (1978) Relationship between the plasma glucose level and glucose uptake in the conscious dog. Metabolism 27: 787-791

14. Wilcoxon F (1947) Probability tables for individual comparisons by ranking methods. Biometrics 3: 119-122

15. Shah JH, Wongsurawat N, Aran PP, Motto GS, Bowser EN (1977) A method for studying acute insulin secretion and glucose tolerance in unanesthetized and unrestrained rats. The effects of mild stress on carbohydrate metabolism. Diabetes 26: $1-6$ 
16. Young JB, Landsberg L (1979) Sympathoadrenal activity in fasting pregnant rats. Dissociation of adrenal medullary and sympathetic nervous system responses. J Clin Invest 64: 109-116

17. Herrera E, Knopp RH, Freinkel N (1969) Urinary excretion of epinephrine and norepinephrine during fasting in late pregnancy in the rat. Endocrinology 84: 447-450

18. Kahn CR (1978) Insulin resistance, insulin insensitivity and insulin unresponsiveness: a necessary distinction. Metabolism 27 [Suppl 2]: 1893-1902

19. Owen OE, Felig P, Morgan AP, Wahren J, Cahill GF jr (1969) Liver and kidney metabolism during prolonged starvation. J Clin Invest 48: 574-583

20. Domont LA, Freinkel N, Baumann G (1978) Insulin receptors in liver are decreased in pregnancy. Clin Res 26: 479 A

21. Soman V (1979) Heterogeneity of insulin receptor changes in pregnancy. Diabetes 28: 393

22. Flint DJ (1980) Change in the number of insulin receptors of isolated rat hepatocytes during pregnancy and lactation. Biochim Biophys Acta 628: 322-327

23. Bergman EN (1963) Quantitative aspects of glucose metabolism in pregnant and nonpregnant sheep. Am J Physiol 204: 147-152

24. Kalhan SC, D'Angelo LJ, Savin SM, Adam PAJ (1979) Glucose production in pregnant women at term gestation. Sources of glucose for human fetus. J Clin Invest 63; 388-394

25. Boyd RDH, Morriss FH, Meschia G, Makowski EL, Battaglia FC (1973) Growth of glucose and oxygen uptakes by fetuses of fed and starved ewes. Am J Physiol 225: 897-902

26. Beaton GH, Beare J, Ryu MH, McHenry EW (1954) Protein metabolism in pregnant rat. J Nutr 54: 291-304
27. Knopp RH (1978) Fuel metabolism in pregnancy. Contemp Obstet Gynecol 1: 83-90

28. Curtis-Prior PB, Trethewey J, Stewart GW, Hanley T (1969) The contribution of different organs and tissues of the rat to assimilation of glucose. Diabetologia 5: 384-391

29. Rushakoff R, Kalkhoff RK (1979) Effects of pregnancy and sex steriods on skeletal muscle sensitivity to insulin. Clin Res 27: 703

30. Leake NH, Burt RL (1966) Response of rat adipose tissue to insulin during pregnancy. Am J Obstet Gynecol 96: 131-133

31. Knopp RH, Herrera E, Freinkel N (1970) Carbohydrate metabolism in pregnancy. VIII) Metabolism of adipose tissue isolated from fed and fasted pregnant rats during late gestation. J Clin Invest 49: 1438-1446

32. Flint DJ, Sinnett-Smith PA, Clegg RA, Vernon RG (1979) Role of insulin receptors in the changing metabolism of adipose tissue during pregnancy and lactation in the rat. Biochem J 182: 421-427

Received: March 28, 1980 ,

and in revised form: June 25,1980

Dr. J. Girard

Collège de France

Laboratoire de Physiologie

du Développement

11 place Marcelin Berthelot

F-75231 Paris Cedex 05

France 